\title{
Antioxidant Effects of Berchemia berchemiaefolia in Nerve Pain Models
}

\author{
Gil-Hyun Lee ${ }^{1}$, Kyung-Yae Hyun ${ }^{2}$ and Seok-Cheol Choi ${ }^{3, \dagger}$ \\ ${ }^{I}$ Department of Clinical Laboratory Science, Kyungwoon University, Gyungbuk 36190, Korea \\ ${ }^{2}$ Department of Clinical Laboratory Science, DongEui University, Busan 47340, Korea \\ ${ }^{3}$ Department of Clinical Laboratory Science, Catholic University of Pusan, Busan 46252, Korea
}

Berchemia berchemiaefolia (BB) are climbing plants or small to medium-sized trees that live in Africa, Asia and America. We performed the present study to investigate whether oral administration of Berchemia berchemiaefolia extract (BBE) protects SD rats from pain. The SD rat experimental groups were divided into four groups. Two of the animal model groups were fed on BBE $(200 \mathrm{mg} / \mathrm{kg}$ or $100 \mathrm{mg} / \mathrm{kg})$. We performed oral acute toxicity test to determine the optimal oral dose of BBE. To explore if BBE alleviated pain in the SD rat, we undertook the tail flick latency test and formalin test. Additionally, we conducted the anti-oxidative test. The findings of the present study suggest that Berchemia berchemiaefolia extract exhibits strong antioxidant and analgesic activities.

Key Words: Nociceptive action, Berchemia berchemiaefolia, Rat, Nerve pain, Tail flick latency test

\section{INTRODUCTION}

Pain has been defined as an uncomfortable sensory and emotional experience associated with tissue damage (Beltramo et al., 2006). The direct and indirect activity of chemical mediators, such as arachidonic acid metabolites, cytokines, nitric oxide, peptides, serotonin, among others are responsible for the multiplicity of events that occur during pain transmission in both the peripheral and central nervous systems (Cimanga et al., 2001; Cao et al., 2008; Bojovic et al., 2015). Reactive oxygen species (ROS) are involved in sensitization of dorsal horn neurons that plays a fundamentally important role in pain (Connor, 2009; Bojovic et al., 2015). Antioxidant substances are known to increase the threshold of pain perception (Bojovic et al., 2015; Evers,
2017). Accordingly, animal pain situation is classified into two groups: central nervous system and peripheral nervous system, which measurement of anti-nociceptive effect is limited to three stimulations as chemical stimulus, mechanical irritation, and temperature shock (Hogan et al., 2013; Kaulmann and Bohn, 2014). In this context, we conduct tale flick latency test to confirm anti-pain effect for central nerve system and formalin test to confirm it for peripheral nervous system (Kishore et al., 2011).

Berchemia berchemiaefolia is a deciduous tree distributed in Korea and Japan. According to recent studies, it is found to have anti-inflammatory and anti-cancer efficacy through animal experiments ( $\mathrm{Li}$ et al., 2014). As a natural edible substance, it is expected to have less side effects than existing chemosynthetic drugs. This study was conducted under the hypothesis that the pain relief effect of Berchemia berche-

*Received: November 14, 2017 / Accepted: December 6, 2017

${ }^{\dagger}$ Corresponding author: Seok-Cheol Choi. Department of Clinical Laboratory Science, Catholic University of Pusan, 57Oryundae-ro, Bugok 3(sam)-dong, Geimjeong-gu, Busan 46252, Korea.

Tel: +82-51-510-0564, Fax:+82-51-510-0568, e-mail: scchoi@cup.ac.kr

(C) The Korean Society for Biomedical Laboratory Sciences. All rights reserved.

(C) This is an Open Access article distributed under the terms of the Creative Commons Attribution Non-Commercial License (http://creativecommons.org/licenses/by-nc/3.0/) which permits unrestricted non-commercial use, distribution, and reproduction in any medium, provided the original work is properly cited. 
miaefolia is related to the antioxidant effect. To evaluate the impact of the antioxidant efficacy of Berchemia berchemiaefolia, this study used DPPH and xanthine oxidase assay.

\section{MATERIALS AND METHODS}

\section{Chemicals and reagents}

All reagents and standards were of analytical reagent grade unless stated otherwise. 2,2-Diphenyl-1-picrylhydrazyl (DPPH) and xanthine oxidase were purchased from Sigma Chemical Co. All other chemicals and solvents were of analytical grade.

\section{Experimental animals}

Thirty male Sprague-Dawley rats (4 weeks of age, $140 \mathrm{~g}$ average body weight) were purchased from Central Lab Animal Inc (Seoul, Korea). Each animal was individually housed in a cage under standard laboratory conditions of $12 / 12$ hours light/dark cycle at $25^{\circ} \mathrm{C}$ and $60 \%$ humidity and was allowed to access food and water ad libitum for 2 weeks. All experiments were approved by the Ethics Committee of Dong-Eui University and were in accordance with the guidelines of the International Association for the Study of Pain (IASP). Control group and experimental group were categorized as follows; Group I: control group $(n=8)$, Group II: vehicle, formalin induced stimulation, saline oral administration ( $\mathrm{n}=8)$, Group III: formalin induced stimulation, Berchemia berchemiaefolia extract (BBE) oral administration (200 mg/kg rat weight) $(\mathrm{n}=8)$, Group IV: formalin induced stimulation, Berchemia berchemiaefolia extract (BBE) oral administration (100 mg/ $\mathrm{kg}$ ratweight).

This study was approved by the Animal Ethic Committee of the Catholic University of Pusan.

\section{Preparation of Berchemia berchemiaefolia extract}

Berchemia berchemiaefolia was purchased from oriental medicine store in Pusan. We rinsed its leaves clean, dried it in the shade for a week, chopped roots into small pieces by grinder, and chopped sources were lyophilized by freeze dryer. After filling $15 \mathrm{~mL}$ tube with 1 milligrams of lyophilized sample and 10 milligrams of $70 \%$ ethanol, tube whirled into rounded mixed machine for 18 hours. Only supernatant was collected, vaporized in $40^{\circ} \mathrm{C}$ and also lyophilized. Yield of extracted material was $6.6 \%$.

\section{Acute toxicity test}

The procedure is incorporated into the European Community Directive guidelines as the acute toxicity test ( $\mathrm{Li}$ et al., 2014). The rats were subjected to toxicity test using the fixed-dose procedure, which is a sequential testing scheme that was proposed by the British Toxicology Society in 1984 as an alternative for the assessment of acute toxicity via estimation of the Lethal Dose $50\left(\mathrm{LD}_{50}\right)$. Briefly, an initial dose of 5, 50, 500, or 2,000 mg per kg of body weight can be selected to evaluate the toxicity of the substance being investigated. Either 5 or 2,000 $\mathrm{mg}$ per $\mathrm{kg}$ can serve as the starting dose. The procedure was terminated when either toxicity or death was observed.

\section{Tail-flick test}

Tail-flick test was applied as follows (Mfotie et al., 2017). Each animal was placed in a ventilated tube with the tail laid across a wire coil maintained at room temperature (23 $\pm 2^{\circ} \mathrm{C}$ ). The coil temperature was then increased by the passage of an electric current, and the latency for the tail withdrawal reflex was measured. Heat was applied to a portion of the ventral surface of the tail between 4 and $6 \mathrm{~cm}$ from the tip. Tail-flick latency (TFL) was measured in 5-min intervals until a stable baseline was obtained over three or four consecutive trials. The apparatus was fixed to obtain a baseline TFL at approximately 3 or 9 seconds. Only rats showing stable baseline TFL after up to 6 trials were used in each experiment. Each trial was terminated after 6 or 15 seconds to minimize the possibility of skin damage.

\section{Formalin test}

Experiments were carried out according to previously described method (Mor et al., 2017). SD rat were orally treated with BBE. One hour later, $20 \mu \mathrm{l}$ of $2.5 \%$ formalin was injected subcutaneously into the right hind paw of each rat. Each rat was immediately placed into a glass cylinder to observe the nociceptive behavior. The time spent in licking the injected paw (an index of nociception) was measured in the first phase $(0 \sim 5 \mathrm{~min})$ and second phase (15 30 $\mathrm{min})$ 
after formalin injection. The nociceptive behaviors including licking/biting durations of the injected paw were recorded in 5-min blocks for $60 \mathrm{~min}$ by video camera.

\section{Animal sacrifice and sampling}

The rats were fasted for 24 hours before sacrificing. The weight of the rats was measured and recorded before anesthesia, and they were placed in supine position on a rat operating table (Dong Sew Science, Seoul, Korea). The lower abdomen was incised and 7 $8 \mathrm{~mL}$ blood was collected from the abdominal aorta. A proper amount of blood was taken into an EDTA tube and serum separating tube.

\section{DPPH assay}

The free radical scavenging activity of all the extracts was evaluated by 1, 1-diphenyl-2-picryl-hydrazyl (DPPH) according to the previously reported method (Palle et al., 2016). Briefly, an $0.1 \mathrm{mM}$ solution of DPPH in methanol was prepared and $1 \mathrm{~mL}$ of this solution was added to $3 \mathrm{~mL}$ of the solution of all extracts in methanol at different concentration $(10,20,40,80,160,320 \& 640 \mu \mathrm{g} / \mathrm{mL})$. The mixtures were shaken vigorously and allowed to stand at room temperature for 30 minutes. Then the absorbance was measured at $517 \mathrm{~nm}$ using a UV-VIS spectrophotometer. Ascorbic acid was used as the reference. Lower absorbance values of reaction mixture indicate higher free radical scavenging activity. The capability of scavenging the DPPH radical was calculated by using the following formula.

DPPH scavenging effect $(\%$ inhibition $)=\{(\mathrm{A} 0-\mathrm{A} 1) /$ $\left.\mathrm{A} 0)^{*} 100\right\}$

Where, A0 is the absorbance of the control reaction, and A1 is the absorbance in presence of all of the extract samples and reference. All the tests were performed in triplicates and the results were averaged.

\section{Inhibition of xanthine oxidase}

As described by Cimanaga et al. (2001), the assay mixture, containing $40 \mathrm{mM}$ phosphate buffer, $\mathrm{pH} 7.5,0.2 \mathrm{mM}$ ethylenediaminetetraacetic acid (EDTA), and 5 50 $\mu \mathrm{M}$ xanthine, was incubated in a quartz cuvette at $37^{\circ} \mathrm{C}$ for $2 \mathrm{~min}$. The reaction was started by the addition of $10 \mathrm{mU}$ xanthine oxidase (XOD) and the increase value in absorption at 290 $\mathrm{nm}$ was recorded at $5 \mathrm{~s}$ intervals for $5 \mathrm{~min}$. The compounds were dissolved in DMSO to obtain various concentration of solutions. In any appropriate long period of time, absorbance was increased linearly with time, and the slope was reaction rate $(\mathrm{dA} / \mathrm{min})$. First, inhibition rate against XOD of all kinds of compounds was determined in the concentration of 100 $\mu \mathrm{M}$, and then $\mathrm{IC}_{50}$ values were further measured on the samples whose inhibition rate was more than $50 \%$. The solution of $0.5 \mathrm{~mL}$ methanol, $1.3 \mathrm{~mL}$ phosphate buffer, 0.2 $\mathrm{mL}$ xanthine oxidase and $1.5 \mathrm{~mL}$ xanthine substrate is used as a control. Percentage of inhibition is calculated using the formula:

Inhibition of xanthine oxidase $(\%)=[1-(\mathrm{As} / \mathrm{Ac})] \times 100$ where As and Ac are the absorbance values of the test sample and control, respectively.

\section{Nitric oxide assay}

Animal serum was mixed with an equal volume of Griess reagent $[0.1 \% \mathrm{~N}-(1$-naphthyl) ethylenediamine] in distilled water and $1 \%$ sulfanilamide in 5\% phosphoric acid, 1:1 ratio). After a 10 min incubation period, absorbance was measured at $540 \mathrm{~nm}$ on a micro-plate reader.

\section{Data analysis}

Experimental values are presented as mean \pm SD. Statistical significance was determined by Mann-Whitney test or ANOVA with Bonferroni's post-hoc test using SPSS version 18. $P<0.05$ were considered to be statistically significant $(*<0.05 ; * *<0.01 ; * * *<0.001)$. Different letters are significantly different at $P<0.05$, according to the Fisher's least significant difference (LSD) analysis.

\section{RESULTS}

\section{Demographic characteristics}

Thirty-two male Sprague-Dawley rats (4 weeks age, $140 \mathrm{~g}$ averaged body weight) were used in experiment. Each group had no meaningful differences among three before and after experiments (Table 1).

\section{Toxicity studies}

Oral $\mathrm{LD}_{50}$ of BBE in rats was found to be $>2,000 \mathrm{mg} / \mathrm{kg}$ 
Table 1. Demographic characteristics in four groups

\begin{tabular}{lcccc}
\hline \hline \multirow{2}{*}{ Variable } & \multicolumn{3}{c}{ Group } \\
\cline { 2 - 5 } & Control & Vehicle & BBE 200 mg $/ \mathrm{kg}$ & BBE 100 mg $/ \mathrm{kg}$ \\
\hline Total number $(\mathrm{n})$ & 8 & 8 & 8 & 8 \\
Gender & Male & Male & Male & Male \\
Age (week) & 4 & 4 & 4 & 4 \\
BW before experiment (g) & $138.18 \pm 4.58$ & $139.15 \pm 11.21$ & $140.15 \pm 7.68$ & $136.61 \pm 6.88$ \\
BW after experiment $(\mathrm{g})$ & $151.21 \pm 5.55$ & $153.09 \pm 6.81$ & $153.81 \pm 8.15$ & $149.58 \pm 6.65$ \\
\hline
\end{tabular}

Data are expressed as mean \pm standard deviation (SD).

Abbreviation: Control, normal group; Vehicle, no treatment group; BBE $200 \mathrm{mg} / \mathrm{kg}, 100 \mathrm{mg} / \mathrm{kg}$, Berchemia berchemiaefolia extract treatment group $200 \mathrm{mg} / \mathrm{kg}$ or $100 \mathrm{mg} / \mathrm{kg}$; BW, body weight.

Table 2. Analgesic effect of BBE on the tail flick test

\begin{tabular}{lccc}
\hline \hline \multirow{2}{*}{ Animal groups } & \multicolumn{3}{c}{ Tail-flick latency (sec) } \\
\cline { 2 - 4 } & $\begin{array}{c}10 \text { min. after BBE oral } \\
\text { administration }\end{array}$ & $\begin{array}{c}30 \text { min. after BBE oral } \\
\text { administration }\end{array}$ & $\begin{array}{c}50 \text { min. after BBE oral } \\
\text { administration }\end{array}$ \\
\hline Non-BBE & $5.82 \pm 0.82$ & $5.98 \pm 0.56$ & $6.01 \pm 0.48$ \\
BBE $100 \mathrm{mg} / \mathrm{kg}$ & $6.11 \pm 0.75$ & $6.05 \pm 0.48$ & $6.21 \pm 0.62$ \\
BBE $200 \mathrm{mg} / \mathrm{kg}$ & $5.98 \pm 0.58$ & $6.18 \pm 0.78$ & $6.36 \pm 0.59^{*}$ \\
\hline
\end{tabular}

Abbreviation: Non-BBE (Vehicle), no treatment group; BBE $200 \mathrm{mg} / \mathrm{kg}, 100 \mathrm{mg} / \mathrm{kg}$, Berchemia berchemiaefolia extract treatment group $200 \mathrm{mg} / \mathrm{kg}$ or $100 \mathrm{mg} / \mathrm{kg}$

body weight as administration of BBE at a dose of 2,000 mg/ $\mathrm{kg}$ weight did not produce any mortality in the tested animals In chronic administration of BBE at a dose of $2,000 \mathrm{mg} / \mathrm{kg}$ body weight for 28 days did not produce any pathological changes as compared to normal animals (not shown data).

\section{Tail flick test}

Thermal perception threshold was manifested by tail-flick latency. The hot tail flick test results showed that the mean reaction time increased in a dose related manner reaching a peak at 40 minutes for dose $200 \mathrm{mg} / \mathrm{kg}$ (Table 2). A significant increase in the tail-flick latency was observed after 50 minutes of BBE $200 \mathrm{mg} / \mathrm{kg}(P<0.05)$.

\section{Formalin test}

In the formalin test (Table 3), formalin induced nociception in the vehicle rats versus to the sham operated group $(P<$ $0.05, P<0.01)$. BBE $(100 \mathrm{mg} / \mathrm{kg}, 200 \mathrm{mg} / \mathrm{kg})$ could not significantly inhibit the first phase, but was active in the later phase of formalin-induced pain $(P<0.05, P<0.001)$. BBE
Table 3. Inhibitory effect of BBE treatment on the formalin test

\begin{tabular}{lll}
\hline \hline \multirow{2}{*}{ Animal groups } & \multicolumn{2}{c}{ Paw licking time $(\mathrm{sec})$} \\
\cline { 2 - 3 } & \multicolumn{1}{c}{ Early phase } & Late phase \\
\hline Non-BBE & $104.81 \pm 9.58$ & $295.15 \pm 15.68$ \\
BBE $100 \mathrm{mg} / \mathrm{kg}$ & $108.19 \pm 11.58$ & $241.51 \pm 18.51^{*}$ \\
BBE $200 \mathrm{mg} / \mathrm{kg}$ & $105.12 \pm 10.81$ & $171.54 \pm 10.80^{* *}$ \\
\hline
\end{tabular}

Abbreviation: Non-BBE (Vehicle), no treatment group; BBE 200 $\mathrm{mg} / \mathrm{kg}, 100 \mathrm{mg} / \mathrm{kg}$, Berchemia berchemiaefolia extract treatment group $200 \mathrm{mg} / \mathrm{kg}$ or $100 \mathrm{mg} / \mathrm{kg}$

demonstrated a dose dependent relationship in the formalininduced pain test.

\section{DPPH scavenging effect}

DPPH scavenging activity assay is widely used to evaluate the ability of compounds to scavenge-free radicals or donate hydrogen/electron, and determine the antioxidant activity in foods. At all concentrations, ascorbic acid was shown higher inhibition than BBE fractions (Fig. 1). Among of BBE frac- 
tions, $\mathrm{H}_{2} \mathrm{O}$ fraction was higher antioxidant activity (48.9\% $640 \mu \mathrm{g} / \mathrm{mL})$.

\section{Inhibition of xanthine oxidase}

The impact on XOD activity of compounds was showed in Table 4. Among these compounds, $\mathrm{BBE} \mathrm{H}_{2} \mathrm{O}$ was the strongest in inhibiting XOD activity whose $\mathrm{IC}_{50}$ value (45.15 $\mu \mathrm{M})$ is similar to positive reference substance quercetin $(15.9 \mu \mathrm{M})$, while four substance showed almost no inhibitory activity.

\section{Nitric oxide assay}

Initially, to assess the anti-oxidant and anti-inflammatory

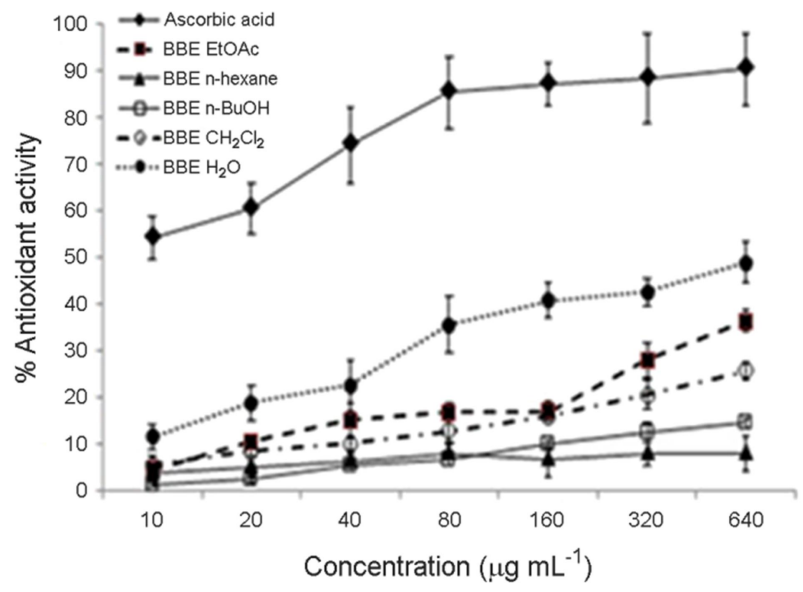

Fig. 1. DPPH scavenging effect of $\mathrm{BBE}$ fractions. $\mathrm{BBE} \mathrm{H}_{2} \mathrm{O}$ fraction was higher antioxidant activity among BBE fractions. Positive control was ascorbic acid. Data represent the mean $\pm \mathrm{SD}$ of three independent experiments; $n$-hexane, methylene chloride $\left(\mathrm{CH}_{2} \mathrm{Cl}_{2}\right)$, ethyl acetate (EtOAc), n-butanol (n-BuOH). effect of BBE, the impact of BBE on NO production in experimental serum was analyzed. After formalin treatment, the production of NO was dramatically increased. However, treatment with BBE markedly reduced NO production (Fig. 2). There was around $27.44 \%$ and $41.86 \%$ reduction in serum $\mathrm{NO}$ production at 100 and $200 \mu \mathrm{g} / \mathrm{kg} \mathrm{BBE}$ oral administration compared with NO production of Vehicle.

\section{DISCUSSION}

We conducted this research into effect of anti-pain for Berchemia berchemiaefolia (BBE). The present study demonstrated that oral treatment with BBE protects SD rats from

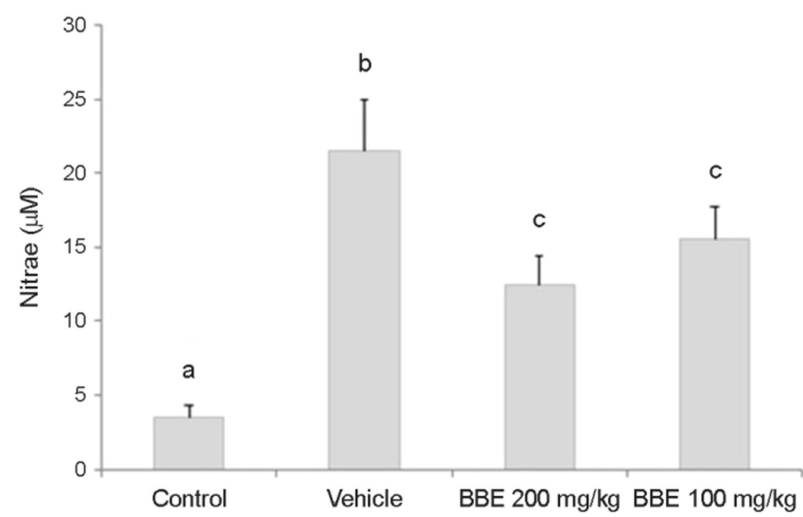

Fig. 2. Production of nitrate oxide in formalin animal model. There was around $27.44 \%$ and $41.86 \%$ reduction in serum $\mathrm{NO}$ production at 100 and $200 \mu \mathrm{g} / \mathrm{kg} \mathrm{BBE}$ oral administration compared with NO production of Vehicle. Data represent the mean \pm SD of three independent experiments; values with different letters are significantly different at $P<0.05$, according to the Fisher's least significant difference (LSD) analysis.

Table 4. Inhibitory effects of the compounds on xanthine oxidase activity

\begin{tabular}{lccc}
\hline \hline & Sample (Fraction) & \% Inhibition $(100 \mu \mathrm{M})$ & $\mathrm{IC}_{50}(\mu \mathrm{M})$ \\
\hline & 0 & - \\
BBE n-hexane & 0 & - \\
$\mathrm{BBE} \mathrm{CH}_{2} \mathrm{Cl}_{2}$ & $11.81 \pm 1.90^{\mathrm{a}}$ & - \\
$\mathrm{BBE} \mathrm{EtOAc}$ & $25.38 \pm 0.85^{\mathrm{a}}$ & $45.15 \pm 2.45$ \\
$\mathrm{BBE}$ n-BuOH & $58.15 \pm 1.48^{\mathrm{c}}$ & $15.9 \pm 1.78$ \\
$\mathrm{BBE} \mathrm{H}_{2} \mathrm{O}$ & $78.99 \pm 3.51^{\mathrm{c}}$ & & \\
Quercetin & & & \\
& & &
\end{tabular}

Data represent the mean \pm SD of three independent experiments; values with different letters are significantly different at $P<0.05$, according to the Fisher's least significant difference (LSD) analysis, n-hexane, methylene chloride $\left(\mathrm{CH}_{2} \mathrm{Cl}_{2}\right)$, ethyl acetate (EtOAc), n-butanol (n-BuOH) 
formalin induced pain. We have expected that $\mathrm{BBE}$ reduces level of pain because BBE has anti-oxidant feature.

First of all, we carried out acute toxicity test of BBE in $\mathrm{SD}$ rat to determine the fixed-dose. The results were that the $\mathrm{LD}_{50}$ of $\mathrm{BBE}$ is more than $2,000 \mathrm{mg} / \mathrm{kg}$, which indicates that $\mathrm{BBE}$ can be categorized as 'unclassified'. BBE may have fewer adverse effects in our experimental animals considering absence of animal death, disease, and organ abnormality. As mentioned above, we conduct tale flick latency test to confirm analgesic effect for central nerve system and formalin test to confirm it for peripheral nervous system (Palle et al., 2016). In the tail flick test, the groups that received $200 \mathrm{mg} / \mathrm{kg}$ of $\mathrm{BBE}$ had shown a significant increase in tail flick latency time. The increase in reaction time of the rats shows that $\mathrm{BBE}$ at the doses given has analgesic activities. The anti-nociceptive effects of BBE might be contributed partly by its action on opioid receptors in the spinal cord (Planjar-Prvan et al., 2004). The formalin-induced test is believed to resemble clinical pain more exactly in comparison with thermal or mechanical stimuli (Rosa et al., 2005; Ray et al., 2015). The first phase results from chemical stimuli of nociceptive afferent fibers, which can be suppressed by morphine (Russo et al., 2016; Siahposht-Khachaki et al., 2017). In the second phase, inflammatory mediators in peripheral tissues induce functional changes in the neurons of the spinal dorsal horn. In this model, BBE inhibited the licking duration of rat in the second phase (Table 2), suggesting BBE exerts anti-nociceptive effect related to peripheral mechanisms.

As a result of our tail flick test, the analgesic properties of BBE could be contributed by its antioxidant property (Srinivasan et al., 2010). Reports have shown the role of oxidative stress in the development of pain / hyperalgesia, and vitamin $\mathrm{C}$, one of the antioxidants, has been shown to inhibit nociceptive transmission by interacting at the level of glutamate receptors in the central nervous system (Straub, 2001). In general, the first-phase response is due to the high level of activity in the primary afferents induced by formalin, and the second phase was considered to be a tonic response resulting from the inflammation factor (Taherian et al., 2010). Also release of a broad range of sensitizers from inflammatory tissue, acting on the related receptors and signaling pathways on the peripheral terminal of nociceptors, induces a process of peripheral sensitization, which is an important neuronal mechanism underlying primary hyperalgesia at the site of injury or inflammation (Toyama et al., 2017). MAPKs, including p38, ERK, and JNK, are a family of serine protein kinases that transduce extracellular stimuli into intracellular posttranslational and transcriptional responses. It is well established that the MAPKs activation may be involved in the modulation of nociceptive information and peripheral and central sensitization produced by intense noxious stimuli through various routes (Umar et al., 2017).

For this reason, therapeutic approaches for treating pain include applications of antioxidant agents, as well as antiinflammatory agent for symptomatic relief (Wang et al., 2016). Suppression of XO activity is one of the therapeutic strategies to reduce pain such as gout. A few XO inhibitors (allopurinol and febuxostat) have been clinically used (Ye et al., 2016). A variety of other antioxidants have also been used as analgesic drug candidates (Zhou et al., 2017). This experimental results show that the water fraction of this material has a strong antioxidant capacity (Fig. 1, Table 4). From this point of view, the analgesic effect of this substance is probably related to the antioxidant capacity of the substance itself. In addition, it is considered that the decrease of the serum NO concentration was involved as the basis of the other anti-pain. It is known that there is a strong relationship between the anti-inflammatory effect and antioxidant ability (Zuntini et al., 2017). However, further studies on the direct mechanism of BBE on antioxidant and anti-inflammatory action are needed.

In conclusion, this study demonstrates that oral admission of BBE prevents the inflammatory pain induced by formalin through antioxidant ability in rat. These findings may have important implications for exploring the roles and mechanisms and for understanding the molecular basis of BBE in analgesia. These results suggest that BBE could be useful to suppress pain in the second phase of the formalin test. It is anticipated that the strong antioxidant activity of BBE caused an anti-inflammatory action, resulting in an analgesic effect. Therefore, our study suggested that BBE would be useful in treatment of inflammation pain as an analgesia drug. 


\section{ACKNOWLEDGEMENTS}

This work was supported by the Brain Busan 21 Project in 2017. This study was supported by the research funds from Catholic University of Pusan.

\section{CONFLICT OF INTEREST}

The authors have no conflicts of interest to disclose.

\section{REFERENCES}

Beltramo M1, Bernardini N, Bertorelli R, Campanella M, Nicolussi E, Fredduzzi S, Reggiani A. CB2 receptor-mediated antihyperalgesia: possible direct involvement of neural mechanisms. European Journal of Neuroscience. 2006. 23: 1530-1538.

Bojovic O, Bramham CR, Tjølsen A. Chronic morphine treatment enhances sciatic nerve stimulation-induced immediate early gene expression in the rat dorsal horn. Acta Neurobiologiae Experimentalis. 2015. 75: 305-313.

Cimanga K, Ying L, De Bruyne T, Apers S, Cos P, Hermans N, Bakana P, Tona L, Kambu K, Kalenda DT, Pieters L, Vanden Berghe D, Vlietinck AJ. Radical scavenging and xanthine oxidase inhibitory activity of phenolic compounds from Bridelia ferruginea stem bark. Journal of Pharmacy and Pharmacology. 2001. 53: 757-761.

Connor M. Allopurinol for pain relief: more than just crystal clearance? British Journal of Pharmacology. 2009. 156: 4-6.

Evers S. Facial pain: Overlapping syndromes. Cephalalgia. 2017. 37: 705-713.

Hogan D, Baker AL, Morón JA, Carlton SM. Systemic morphine treatment induces changes in firing patterns and responses of nociceptive afferent fibers in mouse glabrous skin. Pain. 2013. 154: 2297-2309.

Kaulmann A, Bohn T. Carotenoids, inflammation, and oxidative stress- -implications of cellular signaling pathways and relation to chronic disease prevention. Nutrition Research. 2014. 34: 907-929.

Kishore RK, Halim AS, Syazana MS, Sirajudeen KN. Tualang honey has higher phenolic content and greater radical scavenging activity compared with other honey sources. Nutrition Research. 2011. 31: 322-325.

Li C, Yi LT, Geng D, Han YY, Weng LJ. Hepatoprotective effect of ethanol extract from Berchemia lineate against CCl4induced acute hepatotoxicity in mice. Pharmaceutical Biology. 2014. 53: 767-772.
Mfotie Njoya E, Munvera AM, Mkounga P, Nkengfack AE, McGaw LJ. Phytochemical analysis with free radical scavenging, nitric oxide inhibition and antiproliferative activity of Sarcocephalus pobeguinii extracts. BMC Complementary and Alternative Medicine. 2017. 17: 199-207.

Mor D, Kendig MD, Kang JW, Gemikonakli G, Austin PJ, Kalman E, Corbit LH. Peripheral nerve injury impairs the ability to maintain behavioral flexibility following acute stress in the rat. Behavioral Brain Research. 2017. 328: 123-129.

Palle P, Ferreira FM, Methner A, Buch T. The more the merrier? scoring, statistics and animal welfare in experimental autoimmune encephalomyelitis. Lab Anim. 2016. 50: 427-432.

Pillarisetti S, Khanna I. A multimodal disease modifying approach to treat neuropathic pain-inhibition of soluble epoxide hydro lase (sEH). Drug Discovery Today. 2015. 20: 1382-1390.

Planjar-Prvan M, Bielen I, Baraba R, Buljan R. Pathophysiologic basis of the treatment of neurogenic pain. Acta Medica Croatica 2004. 58: 197-205.

Ray K, Fahrmann J, Mitchell B, Paul D, King H, Crain C, Cook C, Golovko M, Brose S, Golovko S, Santanam N. Oxidationsensitive nociception involved in endometriosis-associated pain. Pain. 2015. 156: 528-539.

Rosa KA, Gadotti VM, Rosa AO, Rodrigues AL, Calixto JB, Santos AR. Evidence for the involvement of glutamatergic system in the antinociceptive effect of ascorbic acid. Neuroscience Letters. 2005. 381: 185-188.

Russo R, Cristiano C, Avagliano C, De Caro C, La Rana G, Raso GM, Canani RB, Meli R, Calignano A. Gut-brain axis: role of lipids in the regulation of inflammation, pain and CNS diseases. Current Medi Chem. Curr Med Chem. 2017. 16. doi: 10.2174/0929867324666170216113756. [Epub ahead of print]

Siahposht-Khachaki A, Pourreza P, Ezzatpanah S, Haghparast A. Nucleus accumbens dopamine receptors mediate hypothalamus -induced antinociception in the rat formalin test. European Journal of Pain. 2017. 21: 1285-1294.

Srinivasan V, Pandi-Perumal SR, Spence DW, Moscovitch A, Trakht I, Brown GM, Cardinali DP. Potential use of melatonergic drugs in analgesia: mechanisms of action. Brain Research Bulletin. 2010. 81: 362-371.

Straub JO. Environmental risk assessment for new human pharmaceuticals in the European Union according to the draft guideline/discussion paper. Toxicology Letters. 2001. 131: 137 -143 .

Taherian A, Sameni H, Sadeghi S, Taherian M. The role of opioid receptors on anti-nociceptive effects of hydroalcoholic extract 
of securigera securidaca L. seed in albino mice. Journal of Pain. 2016. 17: 55.

Toyama S, Shimoyama N, Shimoyama M. The analgesic effect of orexin-A in a murine model of chemotherapy-induced neuropathic pain. Neuropeptides. 2017. 61: 95-100.

Umar AH, Suleiman I, Muhammed H. Effect of low dose lead $(\mathrm{Pb})$ administration on tail immersion test and formalin-induced pain in wistar rats: possible modulatory role of cobalt (II) chloride. Nigerian Journal of Physiological Sciences. 2017. 31: 161-164.

Wang ZY, Liu JG, Li H, Yang HM. Pharmacological effects of active components of chinese herbal medicine in the treatment of Alzheimer's disease: a review. The American Journal of Chinese Medicine. 2016. 44: 1525-1541.

Ye L, Xiao L, Bai X, Yang SY, Li Y, Chen Y, Cui Y, Chen Y. Spinal mitochondrial-derived ROS contributes to remifentanil-induced postoperative hyperalgesia via modulating NMDA receptor in rats. Neuroscience Letters. 2016. 634: 79-86.

Zhou F, Zhang W, Zhou J, Li M, Zhong F, Zhang Y, Liu Y, Wang Y. Involvement of endoplasmic reticulum stress in formalininduced pain is attenuated by 4-phenylbutyric acid. Journal of Pain Research. 2017. 10: 653-662.

Zuntini Viscardi D, Arrigo JD, Correia CA, Kassuya CA, Cardoso CA, Maldonade IR, Argandoña EJ. Seed and peel essential oils obtained from Campomanesia adamantium fruit inhibit inflammatory and pain parameters in rodents. PLOS One. 2017. 12: 1-15.

https://doi.org/10.15616/BSL.2017.23.4.380

Cite this article as: GH Lee, KY Hyun, SC Choi. Antioxidant Effects of Berchemia berchemiaefolia in Nerve Pain Models. Biomedical Science Letters. 2017. 23: $380-387$. 